\title{
Review Paper: Mental Health Challenges in Immigrant and Refugee Children and Adolescents: A Systematic crosshark Review
}

\author{
Katayoon Jahangiri ${ }^{1}$, Shahnaz Tabatabaie ${ }^{2}$, Meysam Safi Keykaleh ${ }^{\text {* }}$
}

1. Department of Health in Disasters and Emergencies, School of Health Safety and Environment, Shahid Beheshti University of Medical Sciences, Tehran, Iran.

2. Department of Ergonomics, School of Health Safety and Environment, Shahid Beheshti University of Medical Sciences, Tehran, Iran

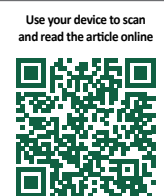

Cftation: Jahangiri K, Tabatabaie Sh, Safi Keykaleh M. Mental Health Challenges in Immigrant and Refugee Children and Adolescents: A Systematic Review. Health in Emergencies and Disasters Quarterly. 2017; 3(1):3-10. https:// doi.org/10.29252/NRIP.HDQ.3.1.3

https://doi.org/10.29252/NRIP.HDQ.3.1.3

Article info:

Received: 20 May 2017

Accepted: 13 Aug. 2017

\section{Keywords:}

Mental health, Refugees, Asylum seekers, Adolescents, Child

\section{ABSTRACT}

Background: Half of the world's refugees comprise children and adolescents. Confronting conflicts and difficulties before, during, and after migration and seeking asylum affect their mental health. The present study aimed at investigating the challenges of mental health of migrant and refugee adolescents and children.

Materials and Methods: A systematic review was conducted in the second half of 2016 using PubMed, Scopus, Magiran, SID, and Google Scholar databases. From the 2014 studies initially selected, 20 articles that specifically attended to examining the mental health of migrant and refugee adolescents and children were finally extracted.

Results: According to previous studies, the refugee adolescents and children encounter much harm. In addition to psychological disorders such as depression, anxiety, post-trauma stress disorder and psychosomatic pains, this group of refugees also suffers from a decline in flexibility and behavioral and cognitive functions. These conditions have been reported more often in refugee adolescents and children who have been separated from their parents or left far away from them.

Conclusion: Before a crisis occurs, policymakers and planners should formulate and implement educational programs along with the participation of parents and teachers in order for children to cope with conditions of disasters, and in order to promote the culture of resilience. The health system, while developing special care programs must prioritize the training of its employees in order to provide services. Most studies have attended to the incidence of symptoms of refugees' psychological disorders, while it seems necessary to conduct intervention studies with the aim of identifying elements of risk and ways to resolve these elements.

* Corresponding Author:

Meysam Safi Keykaleh, PhD Candidate

Address: Department of Health in Disasters and Emergencies, School of Health Safety and Environment, Shahid Beheshti University of Medical Sciences,

Tehran, Iran.

E-mail: meysam.safi@yahoo.com 


\section{Introduction}

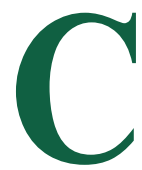

urrently, the frequency of natural disasters such as flood, earthquake, tsunami, tremendous storms, hurricanes, and drought is steadily increasing, and so is the number of man-made calamities such as wars and political conflicts, poverty, hunger, and economic, social and political crises. These disasters and calamities lead to the exodus of vast numbers of people in the form of internal and external migrations $[1,2]$.

According to the United Nations High Commissioner for Refugees (UNHCR), 63.5 million people in the world have been forced to migrate, and about 34000 people per day are forced to migrate due to conflicts, persecution, and harassment. Most migrants seek asylum in the host country. According to the report by UNHCR in 2014, 59 million people were forcibly displaced and 500 thousand people became homeless throughout the world, and these numbers are more than the number of displaced persons in the Second World War. Among these people, 14 million and 400 thousand have sought asylum [3]. Nearly two-thirds of the refugees constitute children and adolescents, which is an alarming rate. For example, nearly $50 \%$ of Syrian refugees are below 18 years of age, including $40 \%$ of children aged less than 12 years [4].

Based on the report by the UNHCR, half of all refugees worldwide are from Somalia, Afghanistan, and Syria (three low-income countries). This report also states that countries like Ghana, Ethiopia, Iran, Lebanon, Pakistan, and Turkey are the top countries that host migrants and refugees [3]. Migration creates important changes in the physical, mental, and social health of the immigrants $[2,5]$. Among immigrants, children and adolescents are more likely to be exposed to unpleasant complications and psychological traumas. This is because of reasons such as inability or limited ability to meet their physical needs, emotional attachments, physiological and psychological differences, age differences, and lack of having experienced adverse conditions [6, 7]. Psychological harms created in children and adolescents relate both to pre-migration conditions, as well as conditions resulting from the time of migration and afterwards.

Given this background, the present study aimed to explain the impact of migration and asylum on various dimensions of mental health, identify various factors and challenges faced by the immigrants, and point out the

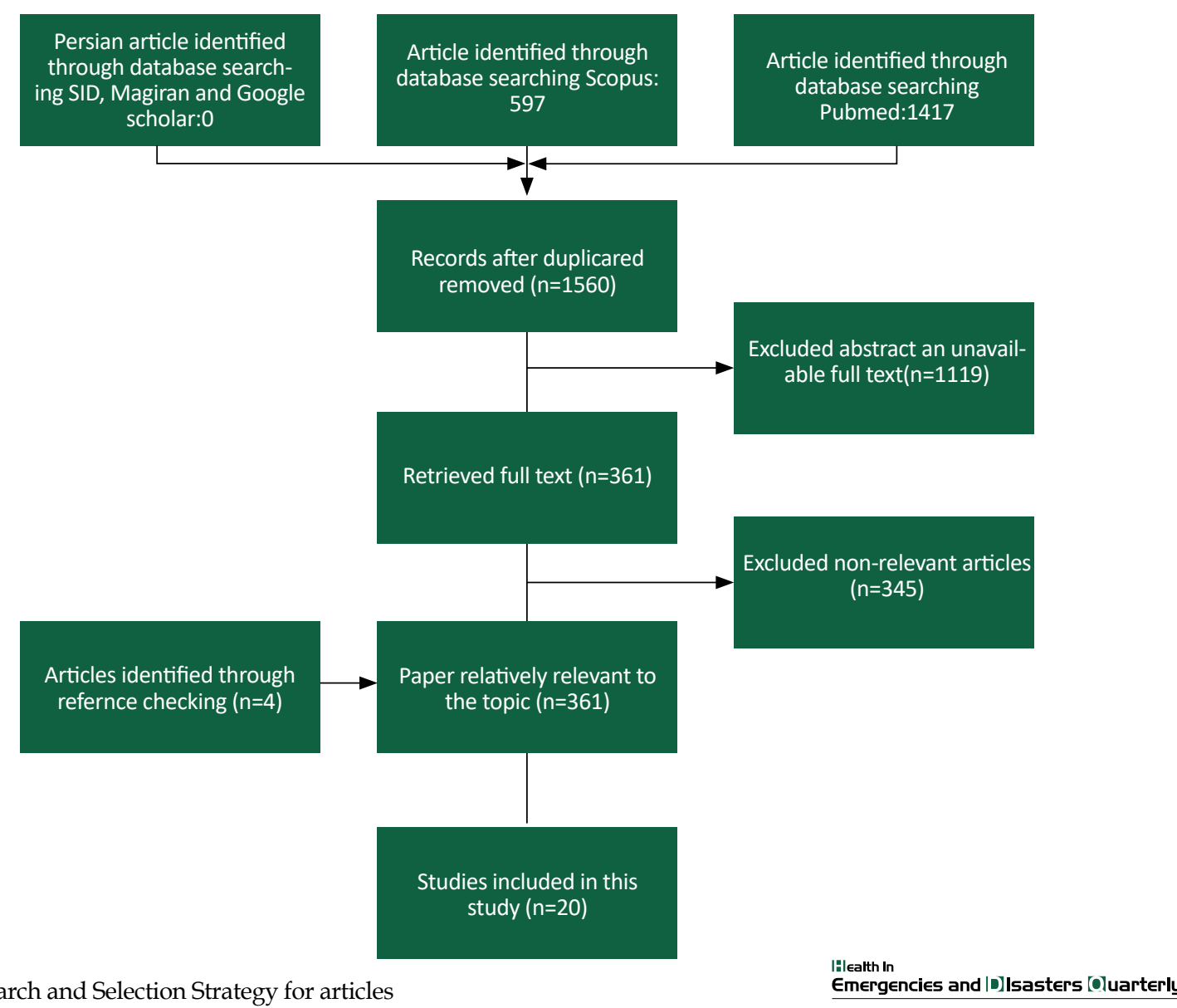

Figure 1. Search and Selection Strategy for articles 
consequences of mental health of children and adolescent migrants and refugees. This study also aimed to identify the challenges of implementing the Third Millennium Development Goals. These goals specify the health and care needs and research gaps and provide relevant recommendations.

\section{Materials and Methods}

This analytical review study used the PUBMED and SCOPUS databases to search for articles. The words "mental health", "migrant", displaced person", "asylum seeker", "refugees", "refugee", “child", “young”, and "adolescent" were used, in separate and combination forms, for searching articles by using AND and OR. Persian language equivalents of these words were also searched in SID, Magiran, and Google Scholar databases based on the search strategy particular for each database. However, no relevant article in the Persian language was found in the Persian language databases. Initially, we obtained 2014 articles in English language databases. Based on the inclusion criteria, from among 1560 articles, 361 articles having complete texts were extracted.

Here, the exclusion criteria were non-availability of complete texts, irrelevant titles, and content different from that intended (Figure 1). Thus, after implementing the search strategies, inclusion and exclusion criteria, and cross-check evaluation method, only 20 articles were finally selected for analysis.

\section{Results}

In the past decade, military conflicts have destroyed the lives of many children and adolescents. In addition to wars, adverse conditions, and economic and social pressures, the frequency of natural disasters has also increased in some parts of the world $[1,2,8]$. Generally, one of the strategies to flee from these conditions is to move away from the place of conflict [9]. The clear manifestation of displacement and migration of people takes place either through internally displaced people (inside their own country) or externally displaced people (outside their country). The decision on migration is usually taken by the head of the household. Therefore, children are less likely to voluntarily migrate. Inability to make decisions independently and lack of economic, social, and political independence often lead to major changes in the way the children migrate [10].

Based on the report by the UNHCR, 20 million people have been forced to migrate due to conflicts, warfare, and strife. Of this number, one-third are refugees who cross international borders to migrate and the remaining migrate inside their own country. Migration has considerable impacts on the mental health of children and adolescents [2] because this group is in its growth stages and is exposed to numerous risks and stressful elements [11, 12]. Therefore, as migrant groups, they are recognized as the most exposed to risks [1].

Since there are numerous important variables affecting the mental health of migrant and asylum-seeking children and adolescents, these variables can be divided into three categories based on the stages of migration: before, during, and after migration. Unpleasant accidents often impact children and adolescents, affecting them even until nine years after migration. However, psychological rehabilitation can reduce the symptoms of illness and help them in speedy recovery [13]. Each experience has

Table 1. Factors affecting the mental health of children and adolescents in different stages of migration

\begin{tabular}{|c|c|}
\hline Time Period & Effective Factors \\
\hline Before migration & $\begin{array}{l}\text { Destruction of properties and assets, physical harms and injuries, observing physical harms of others, observ- } \\
\text { ing the death of other children, observing the death of a member of the family [14, 15], separation from the } \\
\text { family, living under hard conditions, violence, persecution and probable harassments, background vulnerabili- } \\
\text { ties such as previous psychological problems, growth disorders, disability, poverty and the family's economic } \\
\text { problems, incompatible emotional relationships between members of the family, and orphans or unaccom- } \\
\text { panied children, or children with unsuitable guardian }[12,16] .\end{array}$ \\
\hline During migration & $\begin{array}{l}\text { Immigration policies and laws of countries regarding migrants and asylum seekers, arresting and imprisoning } \\
\text { the migrants, high cost of obtaining resident status or resettlement in high-income countries, separation from } \\
\text { parents, lack of legal guardians, presence of profitable and opportunistic traffickers, failure to meet the basic } \\
\text { vital needs, climate change, physical harms, violence and persecution, harassment and abuse }[13,17,18] \text {. }\end{array}$ \\
\hline After migration & $\begin{array}{l}\text { Complicated legal procedures to obtain resident status, entry into a new environment, major language differ- } \\
\text { ences, differences in cultural, social, political and educational contexts, discrimination [19], uncertain condi- } \\
\text { tions and situations, difficulties in obtaining food, different educational situation, problems in health care } \\
\text { delivery, difficulty in obtaining working conditions, security threats in low-income countries, complexity of the } \\
\text { social environment in high-income countries [20], violence, harassment, neglect, and disrespect [21, 22]. }\end{array}$ \\
\hline
\end{tabular}


particular effects because the traumatic and unusual experiences manifest themselves in the form of cumulative and compounding stressors and cause different psychological consequences in children [12]. For example, separation from parents has a direct relationship with post-trauma stress syndrome $[14,15]$.

Unpleasant accidents that parents experience even before the birth of the child can also affect the children. Therefore, it is certain that if a person during childhood witnesses his or her parents being subjected to persecution and harassment or torture, disappearance of parents or the child becomes separated from them, the child would have bitter experiences more often and would experience more psychological health syndromes $[23,24]$. This separation will be a certain prognosis of mental disorders, poor social adjustment, and feeling of humiliation. It has been shown that such impacts can be observed up to three and a half years after resettlement in the new country. This may be partly because, in the absence of the family, the children will be deprived of many supports including access to social resources and facilities, education and proper immigration conditions and etc.; On the other hand, children whose parents were employed or had enjoyed appropriate economic and social conditions prior to the disaster and migration would suffer from adverse psychological effects due to loss of the previous comfortable situation [25-28].

In general, the more vexing and tormenting are the accidents prior to migration, the more difficult it is for immigrant children to adjust to the new conditions. This is because the events before migration would manifest themselves even in the form of sleep disorders, pervasive and recurring anxiety, and psychological problems such as depression and introversion and extroversion disorders $[15,29]$. The factors that cause psychological distresses in refugee children mainly include post-traumatic stress disorder, depression, and symptoms such as irritability, sleep problems, psychosomatic pains, restlessness, behavioral disorders, introversion and extroversion [20, 30-32]. However, the most important psychological disorder seen in refugee children and adolescents is post-traumatic stress disorder, followed by depression [21].

\section{Mental health of refugees and variables}

On reviewing the selected studies, two groups of variables were determined: variables affecting the mental health of refugees and variables that lacked in relevance or impact and needed further study. Gener- ally, the mental health risk factors for refugee children are categorized into three groups: individual, social, and environmental (Table 1).

\section{Individual variables}

One of the effective individual variables is confronting the violence because the experience of adverse events is associated with the probability of an increase in mental disorders in refugee children. The rate of post-traumatic stress disorder has been reported to be directly related to the individual experiences of injurious accidents, especially in those who experienced these accidents away from their original place of residence [28].

Age and gender are other individual factors. In our review, a direct connection was not found between the children's age and psychological disorders. This may be because of the presence of many mutable variables such as the age at which a person experiences adverse and unpleasant accidents, age at the time of migration, different educational and resettlement policies etc. The nature and the length of time a person faces adverse conditions have different impacts on the reaction and response of the persons affected by them at different periods of their life. For example, children exposed to conflicts during their growth period are more likely to suffer from cumulative adversity, which would cause more psychological problems and affect their capacity and resilience. However, the adolescents exposed to short-term conflicts have acquired an experience that would help them to better tolerate long-term conflicts.

The role of caregiver or attendant has been examined in various studies. A study has showed that the symptoms of post-traumatic stress disorder are seen more often with the increase in age of the individual. However, the children who were accompanied by older people faced less difficulty during the transition. Most children who had guardians or attendant could receive their resettlement permit. But children at a lower age and unaccompanied, i.e., without an attendant or a caregiver, had to face the possibility of being deported from the new country after they reach 18 years of age since they could not receive resettlement permits $[15,22,33,34]$.

As regards to gender and psychological functions in immigrant children and adolescents, the results of studies are varied. But in most studies, the prevalence of mental health disorders, especially depression and introversion problems, was higher in girls than those in boys [33, 35, 36]. Educational level was another individual variable that was not much related to psychological disorders 
and behavioral problems. However, the results of some studies indicate that the level of compatibility with new conditions is higher in individuals with higher levels of education. On the other hand, in people with higher levels of education, a higher rate of post-traumatic stress disorder was observed. This indicates that further studies are needed in this regard $[22,37]$.

\section{Familial variables}

Family solidarity and support are also important factors in reducing the children's psychological disorders because the family is a key aspect for immigrant adolescents. Therefore, family resilience is important and effective [38-41]. Since families in isolation cannot have any activity, increase in resilience and accepting the new social conditions can provide social supports for children [42]. Children whose parents have divorced after migration show more psychological symptoms as compared with other children. Social and economic stability of families is also important because the economic worries of the parents have adverse impacts on the health of the immigrant children. Studies are needed to be conducted regarding other familial variables; for example, in some studies, the educational level of the family has been shown to be effective while other studies have showed it to have no effects $[16,24,43]$.

\section{Social and environmental variables}

The uncertain situation of places for refugees and the frustration in meeting the needs and requirements have a direct connection with depression and introversion. Lower levels of violence and discrimination have a significant effect on children's self-belief. Boys are more exposed to discrimination, which could lead to weaker psychological functions in them [43]. These discriminations would further lead to an increase in post-traumatic stress disorder and depression. If communications between children are strengthened and preserved, their mental health can be improved $[2,44]$.

\section{Educational environment and school}

A major part of the life of children involves the school. Natural disasters and wars disrupt the educational conditions of children. For example, in Syria, the war disturbed the educational environment in most places and almost ruined the educational institutions in some other places. From every four schools, one school was completely destroyed during the war in Syria. During the school year 2014-2015, $51 \%$ of children were deprived of schooling. This problem created a crisis in education for school-age children and had more impact on Syrian girls than on Syrian boys [4].

Also, there is a high probability that refugee and migrant children would be deprived of schools after migration. In the year 2014, more than two-thirds of schoolaged refugee children in Turkey lacked access to schools and educational services. Although the availability of educational conditions and school is a required condition, they would not suffice alone. The feeling of safety in school reduces the levels of risk for children toward suffering from post-traumatic stress disorder, supports them against suffering from depression and anxiety, and strengthens their self-belief. Also, it is necessary that communication should be established between schools and the children's families.

In a study, it has been shown that organizing meetings in groups where children can describe their concerns in front of teachers, professional experts, and specialists in mental health can improve the condition of hyperactive children and reduce the symptoms of emotional disorders [28, 41]. Another importance of education for children and adolescents is that the basic educational needs are provided for in line with the second development goal of the Third Millennium, which is public access to preliminary education $[45,46]$.

\section{Cultural environment}

Children who migrate from various countries to one location have differences in terms of traumatic accidents that they had experienced and their conditions before migration. However, a part of these differences in the incidence of psychological disorders relates to differences in their culture and language $[35,47]$. Acculturation is a slow, continuous, and time-consuming process and requires capacities and special subtleties and intricacies. In addition, it is difficult to measure in terms of quantity. Separation from one's own culture and acceptance of the new culture and values in the host country are not a predictor of psychological compatibility. Nevertheless, some degrees of acceptance of the new culture will have a supporting role and will increase the psychological compatibility of the refugee children. However, if the child or the adolescent is placed in a state of confusion between accepting and not accepting the culture of the new country, he or she will suffer from many psychological issues [39, 48].

\section{Religious and racial backgrounds}

The presence of religious beliefs and commitments in the societies is connected with the lower levels of anxi- 
ety and depression. Among the people of Southeast Asia, the Christian and Muslim refugee adolescents demonstrated less introversive behaviors. Spiritual beliefs in the occurrence of disasters and adverse incidence are important. The connection between religions, beliefs, faith etc., with feelings of danger and resilience is very complicated. However, studies that have attended to this issue do not exist [41, 43, 49].

\section{Conclusion}

From among the eight goals of the Third Millennium Development Goals, four goals are completely related to children and adolescents. The first goal is to reduce poverty and hunger. A few studies have examined the impact of migration and asylum seeking on the poverty suffered by refugees. Many of the conditions conducive to migration such as war and natural disasters disrupt economic conditions and impede the supply of basic needs of people, especially children and adolescents. On the other hand, the improper situation before, during, and after migration and asylum confronts the second goal of the Third Millennium Development Goals with challenges by creating disorder in the educational situation of the migrants and refugees. Another challenge is the increase in the incidence and outbreak of diseases, especially infectious diseases. This has increased the mortality rate of children due to heightened vulnerability and inappropriate hygienic conditions that distance the world from attaining goals 4 and 6 of the Third Millennium Development Goals.

Prior to the occurrence of crises, policy makers and planners should formulate and implement educational plans along with the help of parents and teachers in order for children to cope with disastrous conditions and promote the culture of resilience. While formulating special care programs, the health system should place the training of its own personnel in priority for the purpose of providing services.

All children need grown ups in order to identify their own mental health problems and receive suitable cares. Prevailing over the existing obstacles in the way of identifying and providing care services, is a vital issue. Countries admitting refugees are obliged to provide appropriate asylum conditions and social supports for refugees. Therefore, it is necessary that such countries should provide suitable lodgings to the refugees and other social supports by considering the aspects related to the prevention of violence and for respect toward the dignity of refugees. Moreover, the availability of centers of mental health and educational units with appropriate cultural, social and legal environments and with the participation of refugees' parents can alleviate the sufferings of refugee children and adolescents.

Most studies have investigated the prevalence of symptoms of psychological disorders in refugees. Studies have also identified the elements of risk and ways to remove these elements. The absence of studies on the mental health of refugee children and adolescents is felt in these regards. Researchers need to examine the hygienic and health conditions of refugees and provide solutions for improving those conditions. In addition, there is also the need to conduct face-to-face interviews with the refugees to hear their problems, feelings and needs. Since it seems that the political dimensions have overshadowed the studies in this field, there is a need for the entry of independent international organizations to provide all-encompassing supports for the researchers to conduct the needed studies in this field.

\section{Acknowledgements}

This research did not receive any specific grant from funding agencies in the public, commercial, or not-forprofit sectors. The authors would like to thank all experts who helped us in the study.

\section{Conflict of Interest}

The authors declared no conflicts of interest.

\section{References}

[1] Fazel M, Reed RV, Panter Brick C, Stein A. Mental health of displaced and refugee children resettled in high income countries: Risk and protective factors. The Lancet. 2012; 379(9812):266-82. doi: 10.1016/s0140-6736(11)60051-2

[2] Derluyn I, Mels C, Broekaert E. Mental health problems in separated refugee adolescents. Journal of Adolescent Health. 2009; 44(3):291-7. doi: 10.1016/j.jadohealth.2008.07.016

[3] United Nations High Commissioner for Refugees (UNHCR). Figures at a Glance [Internet]. 2016 [Updated 2017 June 19]. Available from: http://www.unhcr.org/figures-ata-glance.html

[4] Sirin SR, Rogers Sirin L. The educational and mental health needs of Syrian refugee children. Washington, D.C.: Migration Policy Institute; 2015.

[5] Gruebner O, Lowe SR, Sampson L, Galea S. The geography of post disaster mental health: Spatial patterning of psychological vulnerability and resilience factors in New York City 
after Hurricane Sandy. International Journal of Health Geographics. 2015; 14(1):16. doi: 10.1186/s12942-015-0008-6

[6] Peek L, Stough LM. Children with disabilities in the context of disaster: A social vulnerability perspective. Child Development. 2010; 81(4):1260-70. doi: 10.1111/j.14678624.2010.01466.x

[7] Hebebrand J, Anagnostopoulos D, Eliez S, Linse H, PejovicMilovancevic M, Klasen $\mathrm{H}$. A first assessment of the needs of young refugees arriving in Europe: What mental health professionals need to know. European Child \& Adolescent Psychiatry. 2015; 25(1):1-6. doi: 10.1007/s00787-015-0807-0

[8] Reeves RR, Parker JD, Konkle Parker DJ. War related mental health problems of today's veterans: New clinical awareness. Journal of Psychosocial Nursing and Mental Health Services. 2016; 43(7):18-28. PMID: 16116923

[9] Williams R. The psychosocial consequences for children of mass violence, terrorism and disasters. International Review of Psychiatry. 2007; 19(3):263-77. doi: 10.1080/09540260701349480

[10] Guarnaccia PJ, Lopez S. The mental health and adjustment of immigrant and refugee children. Child and Adolescent Psychiatric Clinics of North America. 1998; 7(3):537-53.

[11] Garmezy NE, Rutter ME. Stress, coping, and development in children. Paper presented at the Seminar on Stress and Coping in Children. 11 January 1979, Stanford, California, United States.

[12] Bronstein I, Montgomery P. Psychological distress in refugee children: A systematic review. Clinical Child and Family Psychology Review. 2011; 14(1):44-56. doi: 10.1007/s10567010-0081-0

[13] Montgomery E. Trauma and resilience in young refugees: A 9 year follow up study. Development and Psychopathology. 2010; 22(02):477. doi: 10.1017/s0954579410000180

[14] Hollins K, Heydari H, Grayson K, Leavey G. The mental health and social circumstances of Kosovan Albanian and Albanian unaccompanied refugee adolescents living in London. Diversity \& Equality in Health and Care. 2007; 4:277-85.

[15] Bean T, Derluyn I, Eurelings Bontekoe E, Broekaert E, Spinhoven P. Comparing psychological distress, traumatic stress reactions, and experiences of unaccompanied refugee minors with experiences of adolescents accompanied by parents. The Journal of Nervous and Mental Disease. 2007; 195(4):288-97. doi: 10.1097/01.nmd.0000243751.49499.93

[16] Fazel M, Reed RV, Panter Brick C, Stein A. Mental health of displaced and refugee children resettled in high income countries: Risk and protective factors. The Lancet. 2012; 379(9812):266-82. doi: 10.1016/s0140-6736(11)60051-2

[17] Kirkcaldy BD, Shephard RJ, Siefen RG. The relationship between physical activity and self-image and problem behaviour among adolescents. Social Psychiatry and Psychiatric Epidemiology. 2002; 37(11):544-50. doi: 10.1007/s00127-0020554-7

[18] Feijen L. The challenges of ensuring protection to unaccompanied and separated children in composite flows in europe. Refugee Survey Quarterly. 2008; 27(4):63-73. doi: 10.1093/ rsq/hdn049
[19] Goldin S, Levin L, Persson LÅ, Hägglöf B. Stories of prewar, war and exile: Bosnian refugee children in Sweden. Medicine, Conflict and Survival. 2001; 17(1):25-47. doi: $10.1080 / 13623690108409553$

[20] Gerritsen AAM, Bramsen I, Devillé W, van Willigen LHM, Hovens JE, van der Ploeg HM. Physical and mental health of Afghan, Iranian and Somali asylum seekers and refugees living in the Netherlands. Social Psychiatry and Psychiatric Epidemiology. 2006; 41(1):18-26. doi: 10.1007/s00127-005-0003-5

[21] Heptinstall E, Sethna V, Taylor E. PTSD and depression in refugee children. European Child \& Adolescent Psychiatry. 2004; 13(6):373-80. doi: 10.1007/s00787-004-0422-y

[22] Bean TM, Eurelings Bontekoe E, Spinhoven P. Course and predictors of mental health of unaccompanied refugee minors in the Netherlands: One year follow-up. Social Science \& Medicine. 2007; 64(6):1204-15. doi: 10.1016/j.socscimed.2006.11.010

[23] Daud A, af Klinteberg B, Rydelius P-A. Resilience and vulnerability among refugee children of traumatized and nontraumatized parents. Child and Adolescent Psychiatry and Mental Health. 2008; 2(1):7. doi: 10.1186/1753-2000-2-7

[24] Montgomery E, Foldspang A. Validity of PTSD in a sample of refugee children: Can a separate diagnostic entity be justified. International Journal of Methods in Psychiatric Research. 2006; 15(2):64-74. doi: 10.1002/mpr.186

[25] Giacaman R, Abu Rmeileh NME, Husseini A, Saab H Boyce W. Humiliation: The invisible trauma of war for Palestinian youth. Public Health. 2007; 121(8):563-71. doi: 10.1016/j.puhe.2006.10.021

[26] Morgos D, Worden JW, Gupta L. Psychosocial effects of war experiences among displaced children in Southern Darfur. OMEGA - Journal of Death and Dying. 2008; 56(3):229-53. doi: 10.2190/om.56.3.b

[27] Almqvist K, Broberg AG. Mental health and social adjustment in young refugee children y $3 \frac{1}{1} / 2$ years after their arrival in Sweden. Journal of the American Academy of Child \& Adolescent Psychiatry. 1999; 38(6):723-30. doi: 10.1097/00004583199906000-00020

[28] Geltman PL, Grant Knight W, Mehta SD, Lloyd Travaglini C, Lustig S, Landgraf JM, et al. The lost boys of Sudan. Archives of Pediatrics \& Adolescent Medicine. 2005; 159(6):585 doi: 10.1001/archpedi.159.6.585

[29] Hjern A, Angel B, Höjer B. Persecution and behavior: A report of refugee children from Chile. Child Abuse \& Neglect. 1991; 15(3):239-48. doi: 10.1016/0145-2134(91)90068-o

[30] Fazel M, Wheeler J, Danesh J. Prevalence of serious mental disorder in 7000 refugees resettled in western countries: A systematic review. The Lancet. 2005; 365(9467):1309-14. doi 10.1016/s0140-6736(05)61027-6

[31] Carswell K, Blackburn P, Barker C. The relationship between trauma, post migration problems and the psychological well being of refugees and asylum seekers. International Journal of Social Psychiatry. 2011; 57(2):107-19. doi: $10.1177 / 0020764008105699$

[32] Lindert J, Carta MG, Schäfer I, Mollica RF. Refugees mental health: A public mental health challenge. The European Journal of Public Health. 2016; 26(3):374-5. doi: 10.1093/eurpub/ ckw010 
[33] Derluyn I, Broekaert E. Different perspectives on emotional and behavioural problems in unaccompanied refugee children and adolescents. Ethnicity \& Health. 2007; 12(2):141-62. doi: 10.1080/13557850601002296

[34] Thienkrua W. Symptoms of posttraumatic stress disorder and depression among children in Tsunami Affected Areas in Southern Thailand. JAMA. 2006; 296(5):549. doi: 10.1001/ jama.296.5.549

[35] Hodes M, Jagdev D, Chandra N, Cunniff A. Risk and resilience for psychological distress amongst unaccompanied asylum seeking adolescents. Journal of Child Psychology and Psychiatry. 2008; 49(7):723-32. doi: 10.1111/j.14697610.2008.01912.x

[36] Reijneveld SA, de Boer JB, Bean T, Korfker DG. Unaccompanied adolescents seeking asylum. The Journal of Nervous and Mental Disease. 2005; 193(11):759-61. doi: 10.1097/01. nmd.0000185870.55678.82

[37] Slodnjak V, Kos A, Yule W. Depression and parasuicide in refugee and Slovenian adolescents. Crisis. 2002; 23(3):127-32 doi: $10.1027 / / 0227-5910.23 .3 .127$

[38] Grgić M, Vidović V, Butković-Soldo S, Vukšić-Mihaljević Ž, Degmečić D, Laufer D. The mental health of children upon their return home after a long displacement period. Collegium Antropologicum. 2005; 29(2):537-42. PMID: 16417158

[39] Kovacev L, Shute R. Acculturation and social support in relation to psychosocial adjustment of adolescent refugees resettled in Australia. International Journal of Behavioral Development. 2004; 28(3):259-67. doi: 10.1080/01650250344000497

[40] Rousseau C, Drapeau A, Platt R. Family environment and emotional and behavioural symptoms in adolescent cambodian refugees: Influence of time, gender, and acculturation. Medicine, Conflict and Survival. 2004; 20(2):151-65. doi: 10.1080/1362369042000234735

[41] Sujoldžić A, Peternel L, Kulenović T, Terzić R. Social determinants of health: A comparative study of Bosnian adolescents in different cultural contexts. Collegium Antropologicum. 2006; 30(4):703-11. PMID: 17243537

[42] Weine S. Family roles in refugee youth resettlement from a prevention perspective. Child and Adolescent Psychiatric Clinics of North America. 2008; 17(3):515-32. doi: 10.1016/j. chc.2008.02.006

[43] Montgomery E. Long term effects of organized violence on young Middle Eastern refugees' mental health. Social Science \& Medicine. 2008; 67(10):1596-603. doi: 10.1016/j.socscimed.2008.07.020

[44] Ellis BH, MacDonald HZ, Lincoln AK, Cabral HJ. Mental health of Somali adolescent refugees: The role of trauma, stress, and perceived discrimination. Journal of Consulting and Clinical Psychology. 2008; 76(2):184-93. doi 10.1037/0022-006x.76.2.184

[45] Sachs J, McArthur J. The Millennium Project: A plan for meeting the Millennium Development Goals. The Lancet. 2005; 365(9456):347-53. doi: 10.1016/s0140-6736(05)17791-5

[46] United Nations. Millennium development goals. New York: United Nations; 2015.

[47] Rousseau C, Drapeau A, Corin E. Risk and protective factors in central American and Southeast Asian refugee children. Journal of Refugee Studies. 1998; 11(1):20-37. doi: 10.1093/jrs/11.1.20

[48] Phinney JS. Ethnic identity in adolescents and adults: Review of research. Psychological Bulletin. 1990; 108(3):499-514. doi: 10.1037/0033-2909.108.3.499

[49] Goodman JH. Coping with trauma and hardship among unaccompanied refugee youths from Sudan. Qualitative Health Research. 2004; 14(9):1177-96. doi: 10.1177/1049732304265923 